\title{
Water movement in layered soils. 2. Experimental confirmation of a simulation model
}

\author{
L. Stroosnijder ${ }^{1}$, H. van Keulen ${ }^{2}$ and G. Vachaud ${ }^{3}$
}

1Department of Soils and Fertilizers, Agricultural University, Wageningen, the $\mathrm{Ne}$ therlands.

2Department of Theoretical Production Ecology, Agricultural University, Wageningen, the Netherlands.

${ }^{3}$ Laboratoire de Mécanique des Fluides des Solides et des Sols, Université de Grenoble, France.

Received: 10 December 1971

\section{Summary}

The simulation model written in CSMP (Continuous System Modelling Program) described by van Keulen and van Beek (1971) is used for predicting the rain infiltration front in a layered soil. Experimental results are in good agreement with the predicted infiltration behavior. Attention is paid to the small differences between the experimental and the predicted results.

\section{Introduction}

In a previous paper van Keulen et al. (1971) presented a listing and detailed description of a simulation model for the infiltration of water in an unhomogeneous soil. Although the solutions obtained were evaluated by a comparison with other solutions for simplified situations, suitable data for an experimental evaluation were lacking at the time. Such data are now available from experiments proceeded in Grenoble.

In the present paper, the data nput, the simulated results and the experimental results are presented and discussed.

\section{Data input}

The simulation model is applied to a layered sandy soil. At the top is a layer of fine sand with a total porosity of 0.335 and with a thickness of $35 \mathrm{~cm}$, separated from a bottom layer consisting of $55 \mathrm{~cm}$ of the same material, by a layer of coarse sand with porosity 0.250 and thickness of $46 \mathrm{~cm}$.

The wetting moisture characteristic and the conductivity-moisture content curves for both the fine and the coarse sand, as supplied by the junior author, are presented in Fig. 1 and 2.

The initial moisture is in the semi-equilibrium state, which results after some days of free drainage with the ground water level at $136 \mathrm{~cm}$ below the soil surface. This profile equilibrates only very slowly after three days, since the coarse layer between top and 


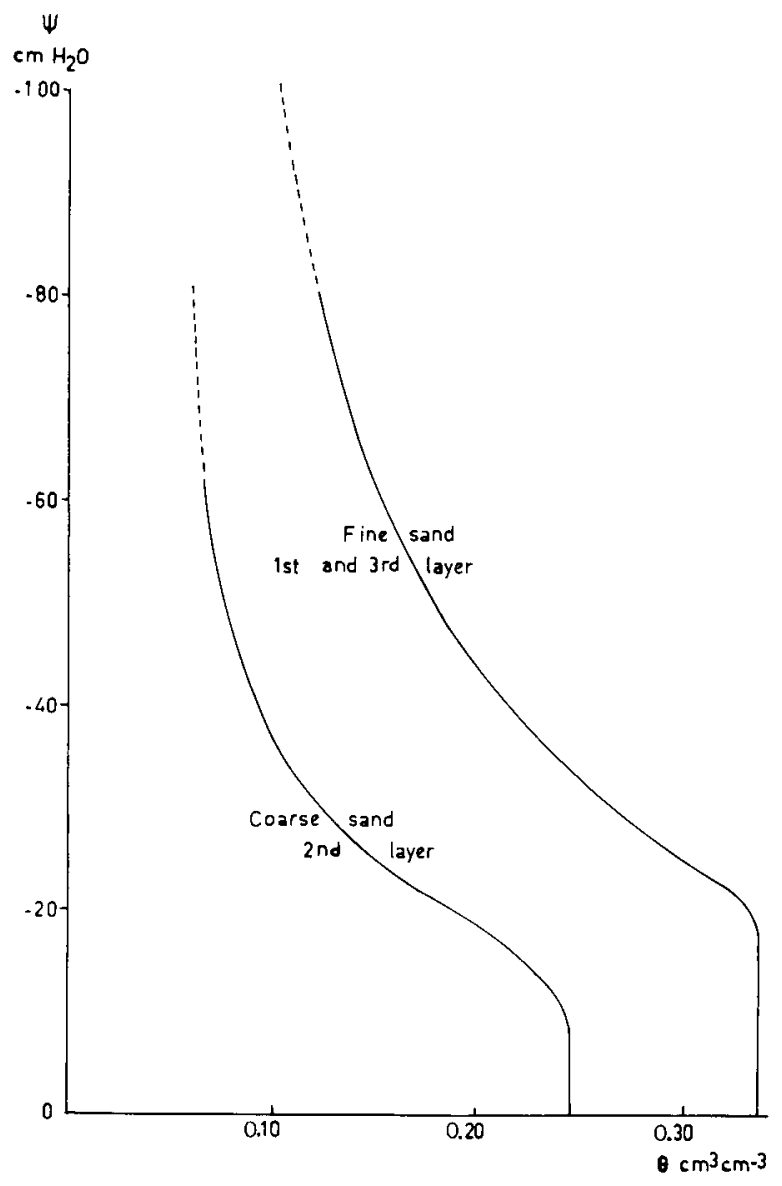

Fig. 1. Water retention curves.

bottom layer has a very low conductivity at the prevailing moisture content of 0.0675 $\mathrm{cm}^{3} . \mathrm{cm}^{-3}$. To this profile $9 \mathrm{~cm}$ rainfall was given at an intensity of $3 \mathrm{~cm} \cdot \mathrm{h}^{-1}$.

For the computation the top soil was divided into 17 compartments of $2 \mathrm{~cm}$ and 1 of 1 $\mathrm{cm}$. The coarse layer contained 23 compartments of $2 \mathrm{~cm}$, and 9 compartments of $2 \mathrm{~cm}$ were considered in the bottom layer.

\section{Computed results}

The computed results are shown in Fig. 3. At the initial stage of infiltration the top layer of fine sand does not reach saturation, but arrives at a moisture content of 0.28 $\mathrm{cm}^{3} . \mathrm{cm}^{-3}$ after 0.25 hours. This value is governed by the conductivity-moisture content relation for a constant flux of $3 \mathrm{~cm} \cdot \mathrm{h}^{-1}$.

Some drainage occurs from the bottom of the top soil into the coarse sand during the first hour. After about 1.5 hours of infiltration the wetting front reaches the coarse sand, and subsequently accumulation of water in the bottom of the topsoil occurs. This is due 


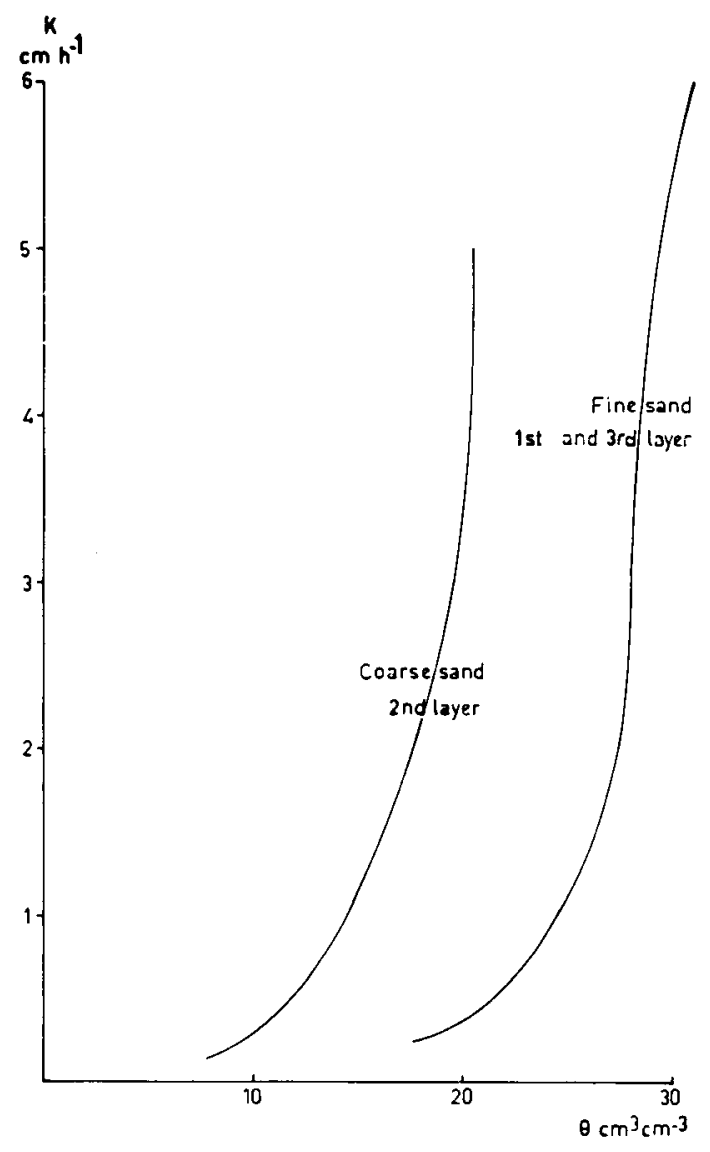

Fig. 2. Conductivity curves.

to the very low capillary conductivity of the coarse layer, as is discussed by Poulouvassilis (1969).

After 3 hours of rainfall some water enters the bottom fine sand layer.

\section{Experimental results}

The experiments were carried out in a laboratory column with fully automatic scanning equipment as described by Vachaud and Thony (1970). The three sandy layers were handpacked in an aluminium column of $10 \mathrm{~cm}$ inner diameter. Each layer was carefully packed homogeneously.

The water content was measured non-destructively during the experiment with a Cs $^{137}$ gamma source, with an accuracy of $0.006 \mathrm{~cm}^{3}$ water per $\mathrm{cm}^{3}$ soil.

Furthermore ten tensiometers connected each one with a pressure transducer, recorded continuously the change of the suction in the column with an accuracy of $0.2 \mathrm{~cm}$ water pressure.

Fine needles inserted into the soil permitted free air escape out of the column. By 


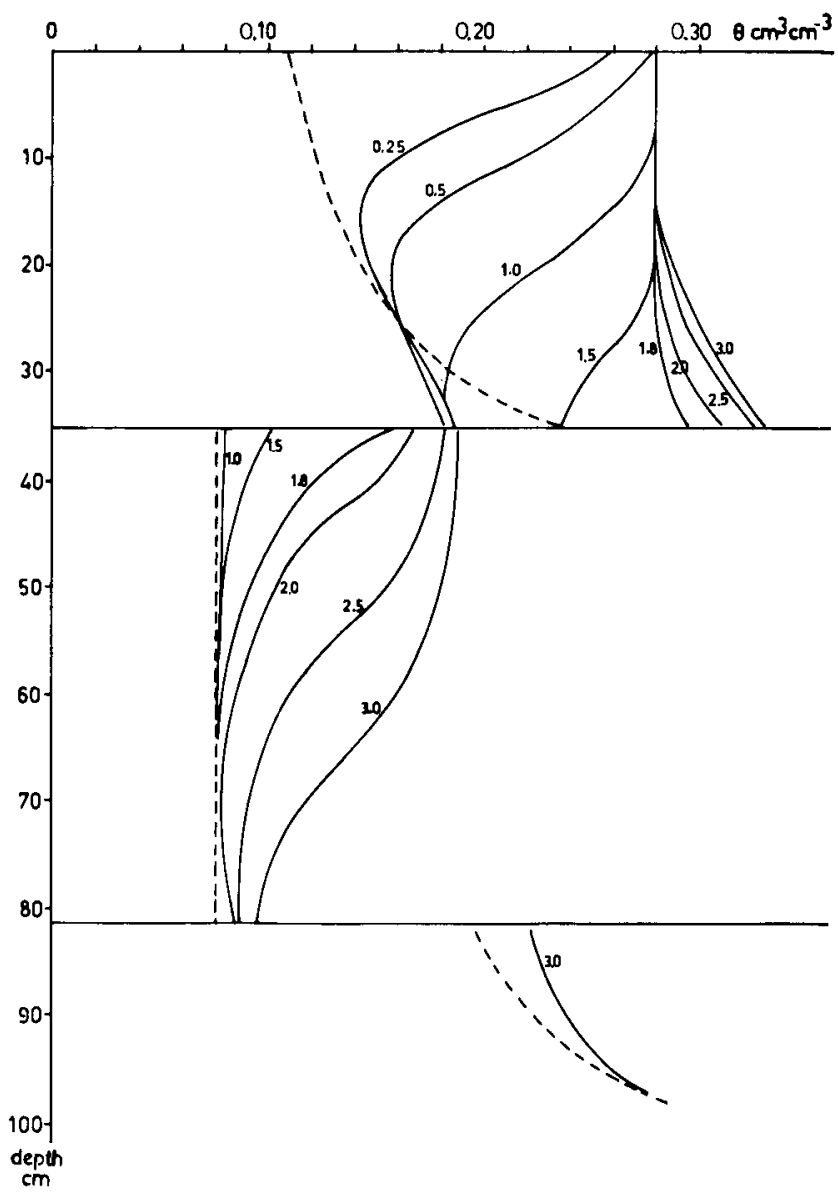

Fig. 3. Simulated rain infiltration. Time (in hours); -..--moisture content initial situation.

connecting some needles to the differential port of the transducers, one can control that the air phase in the soil is continuous under atmospheric pressure.

From the water content and the suction measurements the capillary conductivity is calculated, by means of a dynamic method of Vachaud (1967).

The whole column was initially saturated slowly. A drainage was then achieved by lowering suddenly the piezometric level from 0 to $136 \mathrm{~cm}$ below the soil surface. After three days a semi-equilibrium situation was reached, and the $9 \mathrm{~cm}$ rainfall was applied through the soil surface to this profile.

The water content profiles measured during the infiltration are given in Fig. 4.

\section{Discussion}

Comparison of computed and measured infiltration profiles (Fig. 3 and 4) shows satisfactory agreement though there are some minor deviations. 


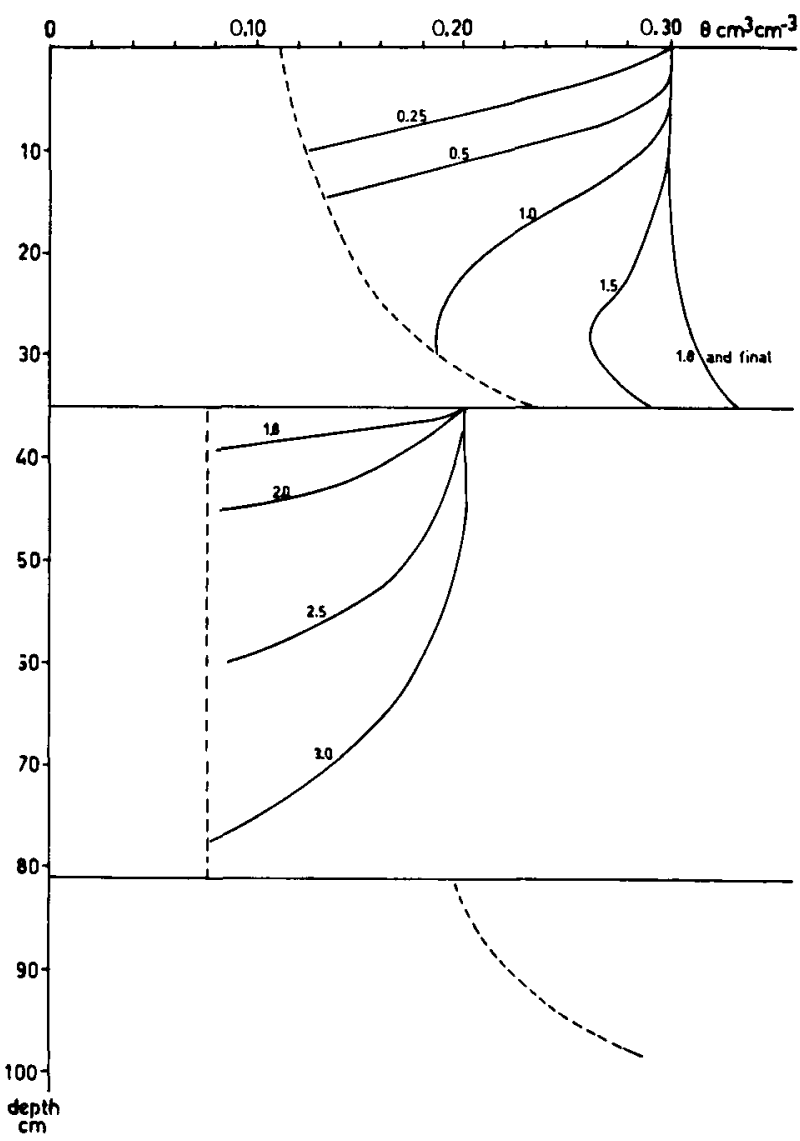

Fig. 4. Measured rain infiltration (after G. Vachaud). Time (in hours). ..... moisture content initial situation.

The constant moisture content in the topsoil in the experimental case is $0.30 \mathrm{~cm}^{3} . \mathrm{cm}^{-3}$, while is was $0.28 \mathrm{~cm}^{3} . \mathrm{cm}^{-3}$ in the computed profiles. The same differences are noted in the coarse sand where a moisture content of $0.20 \mathrm{~cm}^{3} \cdot \mathrm{cm}^{-3}$ at the top was measured, while a value of $0.17-0.19 \mathrm{~cm}^{3} . \mathrm{cm}^{-3}$ was computed. This deviation may originate from a small difference between the substituted $\mathrm{K}-\Theta$ curve and the true $\mathrm{K}-\Theta$ curve. That would mean that the dynamic method of measuring the conductivity according to Vachaud may lead to small deviations.

Another possibility is that the $\mathrm{K}-\Theta$ relation is correct, but that it is impossible to reach in the topsoil such high $\Theta$ values as are measured, because the computed wetting front is necessarily less steep than the measured one.

The slope of the calculated wetting front in the topsoil, but especially in the coarse sand, is less than was measured. There are again two possible explanations. The first one results from the numerical procedure: the division of the column into compartments of finite size, leads to the computation of more smoothed wetting fronts, as is elaboratory shown by van Keulen et al. (1971, Fig. 5). 
In the second place the possibility exists that the neglection of hysteresis in the computation leads to this slope. The $\Psi-\Theta$ curve during the wetting was not unique at each depth, but depended upon the initial water content at that depth. The initial water content profile in the top layer was not constant, since it was a drainage profile. This was not taken into account in the computation, since a unique wetting soil moisture characteristic was used throughout.

As is pointed out before (van Keulen et al., 1971) use is made of a simple arithmetic average of the two conductivities of adjacent compartments to calculate the flux between them. Even at the boundary between the different layers this assumption was used, with the observed good results.

This comparison thus confirms the earlier statement, that the behaviour of soil water can be calculated accurately, if the soil properties are known in sufficient detail.

\section{Acknowledgment}

Helpful comments made by Dr C. T. de Wit and Dr G. H. Bolt in reading the manuscript are gracefully acknowledged. This work was supported in part by a travel grant supplied to the senior author by the Netherlands Organisation for the Advancement of Pure Research (ZWO).

\section{References}

Keulen, H. van \& C. G. E. M. van Beek, 1971. Water movement in layered soils. A simulation model. Neth. J. agric. Sci. 19: 138-153.

Poulouvassilis A.; 1969. Steady state potential and moisture profiles in layered porous media. Soil Sci. 107: $47-52$.

Vachaud, G., 1967. Determination of the hydraulic conductivity of unsaturated soils from an analyses of transient flow data. Wat. Resour. Res. 3: 697-705.

Vachaud, G. \& J. L. Thony, 1971. Hysteresis effects during infiltration and redistribution in a soil column at different water contents. Wat Resour. Res. 7: 111-127.

Wit, C. T. de \& H. van Keulen, 1970. Simulation of transport processes in soils. Rep. Dep. theor. Prod. Ecol., Agric. Univ. Wageningen No 1. 